\title{
Natchez: Inclusão e Sabonetes
}

\author{
Carlos Eduardo Félix da Costa $^{1}$ e Ayelet Danielle Aldouby ${ }^{2}$
}

Resumo: Este artigo apresenta o projeto desenvolvido durante residência artística na cidade de Natchez (Mississipi), a convite com National Endownment for the Arts, Robert Wood Johnson Foundation e XLab IDEAS durante o ano de 2017. As instituições possuem um programa que visa impactar positivamente em comunidades através de projetos artísticos. O resultado final deste processo foram duas instalações, que discutiram questões relacionadas à segregação racial, desaparecimento e autocuidado, em parceria com uma coligação conhecida como 100 Black Women.

Palavras-chave: coparticipação, sabão, magnólia, pérolas

\section{Natchez: Inclusion and Soap}

\begin{abstract}
This article presents the project developed during artistic residency in the city of Natchez (Mississippi), at the invitation of the National Endownment for the Arts, Robert Wood Johnson Foundation and XLab IDEAS during 2017. The institutions have a program that aims to impact positively at communities through artistic projects. The end result of this process was two installations, which discussed issues related to racial segregation, disappearance and self-care, in partnership with a coalition known as 100 Black Women.
\end{abstract}

Keywords: Co-participation, Soap, Magnolia, Pearls

1 Artista plástico e professor pesquisador do Departamento de Artes e Design da PUC-Rio, onde coordena o LINDA Laboratório Interdisciplinar em Natureza, Design e Arte. Vencedor da Bolsa Iberê Camargo (2001), artista visitante na Universidade de Plymouth a convite do Arts Council (2008) e vencedor do Prêmio PIPA (2013). Participante da $7^{a}$ Bienal do Mercosul, 30 Bienal de São Paulo, 13a Bienal de Istambul, $4^{\mathrm{a}}$ Bienal do Fim do Mundo e da «Anozero 19» - Bienal de Arte Contemporânea de Coimbra. Comissionado para residências com os programas Plataforma Atacama (Chile), InSite (México), Fundação Haundenschild Garage (EUA) e XLabs IDEA (EUA). Atualmente desenvolve projeto em parceria com o Instituto República - RJ. Pontifícia Universidade Católica (DAD/PUC-Rio).E-mail: eduardo.felix.costa@ gmail.com. ORCID: https://orcid.org/0000-0002-4148-4430. Lattes iD: http://lattes.cnpq.br/0757744155897986. Rio de Janeiro, Brasil.

2 Curadora especializada em projetos de arte pública e práticas sociais. Consultora do programa de residências Residency Unlimited (Nova lorque). Curadora pela International Artists» Museum dos projetos «Poles Apart, Poles Together» e «Divine In Tent», realizados para a $51^{a}$ e $52^{a}$ Bienais de Veneza e Documenta de Kassel. Consultora e curadora do projeto de arte pública «Re:Construction», comissionado pela Alliance for Downtown (Nova lorque). Atualmente cursa o doutorado em Arte e Educação pela Universidade de Colúmbia (Nova lorque). Publicou o artigo «Seeing the Unseen: A Coming of Age Story Inspired by Soap and Buttons» para a Trends, revista da Associação de Arte e Educação do Texas. Columbia University (Departamento de Arte e Educação / EUA). E-mail: ayelet@ ideasxlab.com. Nova Jersey, EUA. 
Figura 1 Sede da 100 Black Women, cidade de Natchez, 2017.

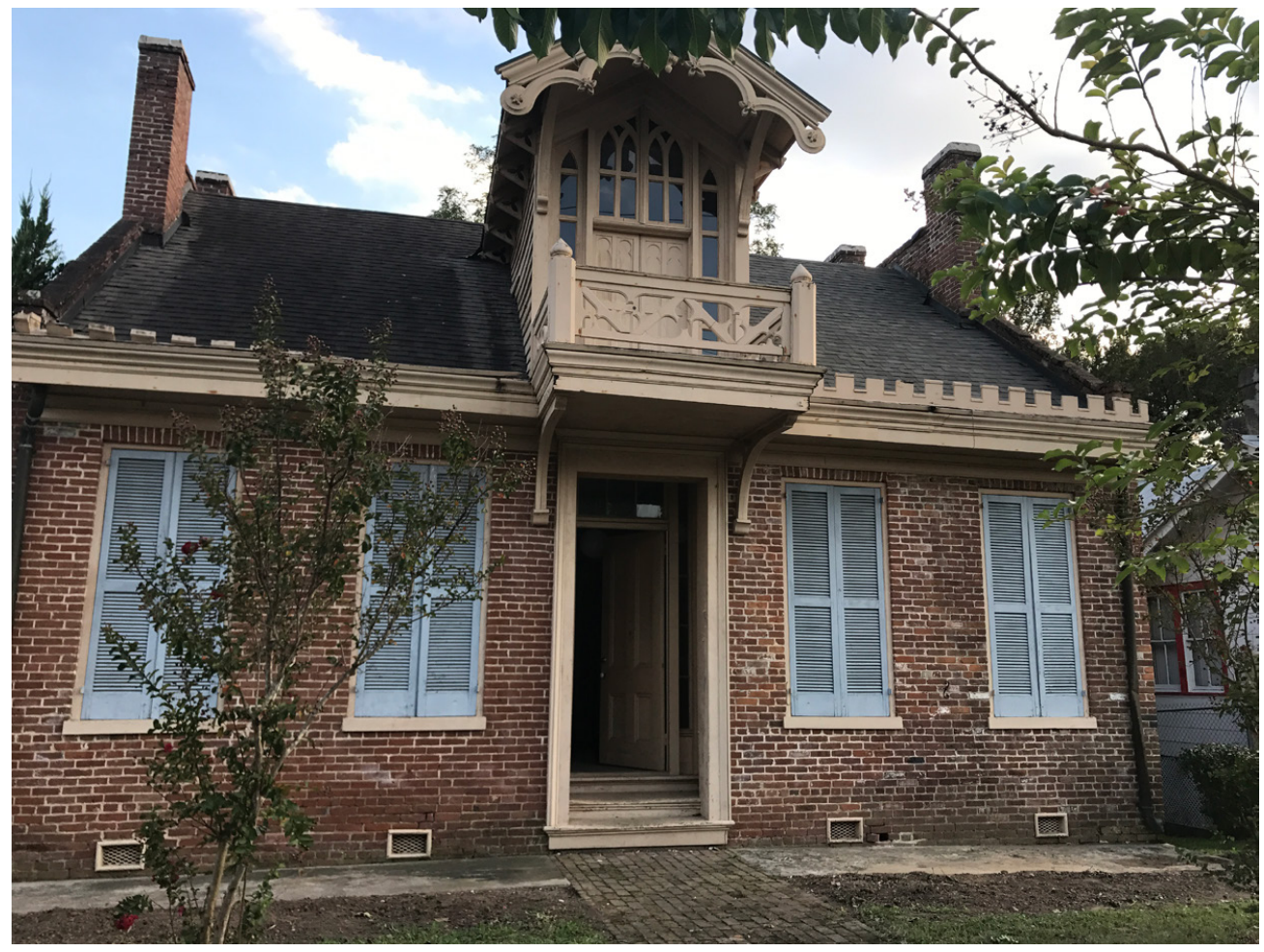

Atravessei o mar Um sol

Da América do Sul Me guia Trago uma mala de mão

Dentro uma oração Um adeus Eu sou um corpo, um ser, um corpo só

Tem cor, tem corte E a história do meu lugar Eu sou a minha própria embarcação

A minha própria sorte Luedji Luna $^{1}$

Artistas que trabalham em residências vivem dilemas curiosos. Os programas variam muito, os períodos de duração e obrigatoriedade de resultantes também. Mas com maior ou menor pressão institucional, os participantes sempre precisam "sair com algo" materializado da investigação. Mesmo sem podermos precisar o que Arte é, ela alimenta uma bem concreta rede de agentes e vinculadores - críticos, curadores, artistas, colecionadores, galerias, museus, fundações privadas e públicas, leilões, revistas, feiras,

1 LUNA, Luedji. Verso da canção “Um corpo no mundo”, 2017. 
bienais, universidades ... - que orbitam em torno do capital. Logo, programas desta natureza dependem dos contornos da forma, sejam quais forem, para manterem-se no processo material de sustento financeiro do campo. O que exige um pouco de pragmatismo e delírio, para manter a bússola da realização em curso. O projeto realizado a convite da XLab IDEAS, através de fundos da National Endowment for the Arts e Robert Wood Johnson Foundation durante o ano de 2017 na cidade de Natchez (Mississipi), foi um exemplo deste instável equilíbrio.

Haviam premissas importantes a serem observadas e de algum modo conectadas. O trabalho deveria engajar comerciantes e/ou artistas locais de ascendência afro-americana, abordar a segregação racial a partir das doenças associadas ao legado colonial e articular um grupo de jovens tuteladas por uma organização conhecida como 100 Black Women². O projeto iniciou-se pela aproximação com a coligação fundada em 1970 em Nova lorque, dentre as muitas iniciativas por igualdade de gênero e raça aceleradas pelo assassinato de Martin Luther King dois anos antes. Atualmente a NC100BW conta com milhares de membras e representação em mais de 25 estados.

As dirigentes da sede de Natchez deveriam aprovar a participação de um artista homem e estrangeiro antes de tudo. Nos encontramos virtualmente no final de 2016. Há uma ideia generalizada e depois confirmada por experiências vividas na cidade, que o Brasil é um país em que a miscigenação "funcionou". A confluência de culturas, clima tropical, futebol e Carnaval, ao menos no Mississipi gerou um imaginário de que negociamos melhor nosso triste legado de preconceitos e privilégios. Esta miragem do que é o nosso país, colaborou para a construção dos vínculos necessários para o projeto avançar. Mas não esqueçamos, havia uma perspectiva periférica em relação a mim, um latino é percebido como também à margem.

Recebi informações sobre a atuação da coligação em Natchez e como ela é responsável por acompanhar dos 8 aos 18 anos jovens pelo meio de encontros quinzenais. Nestas reuniões diversas atividades e assuntos eram abordados, dependendo de festividades no calendário, de eventos pessoais ocorridos com as participantes ou temas que a coligação recebia de suas instancias superiores. A finalidade era sempre contribuir para a formação 
das jovens, preparando-as para os desafios de crescerem numa sociedade machista e segregacionista. Minha principal intermediadora com o grupo de cerca de 15 adolescentes seria Hannah Drake, uma spoken word artist $^{3}$ do Kentucky, também familiarizada com trabalhos de prática social e copartipação. Sua presença, assim como de toda a equipe, foi fundamental tanto para o engajamento do grupo, quanto para ativações posteriores das obras resultantes. Hannah explicitava os conceitos trabalhados, desencabulava o diálogo e gerava sinergia.

Algo que captou bastante a atenção foi o fato de não haver separação etária para as aulas. As mulheres, entre 11 e 17 anos, estavam sempre juntas. Eram tratadas igualmente. As tutoras afirmam que isso gerava uma natural linhagem de cuidado e aconselhamento. Alguns assuntos tabus da passagem da infância para a vida adulta não são partilhados com as mais velhas, mas podiam ser com as colegas um pouco mais experientes. Esse tipo de rede de apoio reforçava a manutenção do grupo para além das reuniões oficiais.

Figura 2 Tutoras, mães e jovens pertencentes a 100 Black Women, cidade de Natchez, 2017. Acima a direita, Hannah Drake.

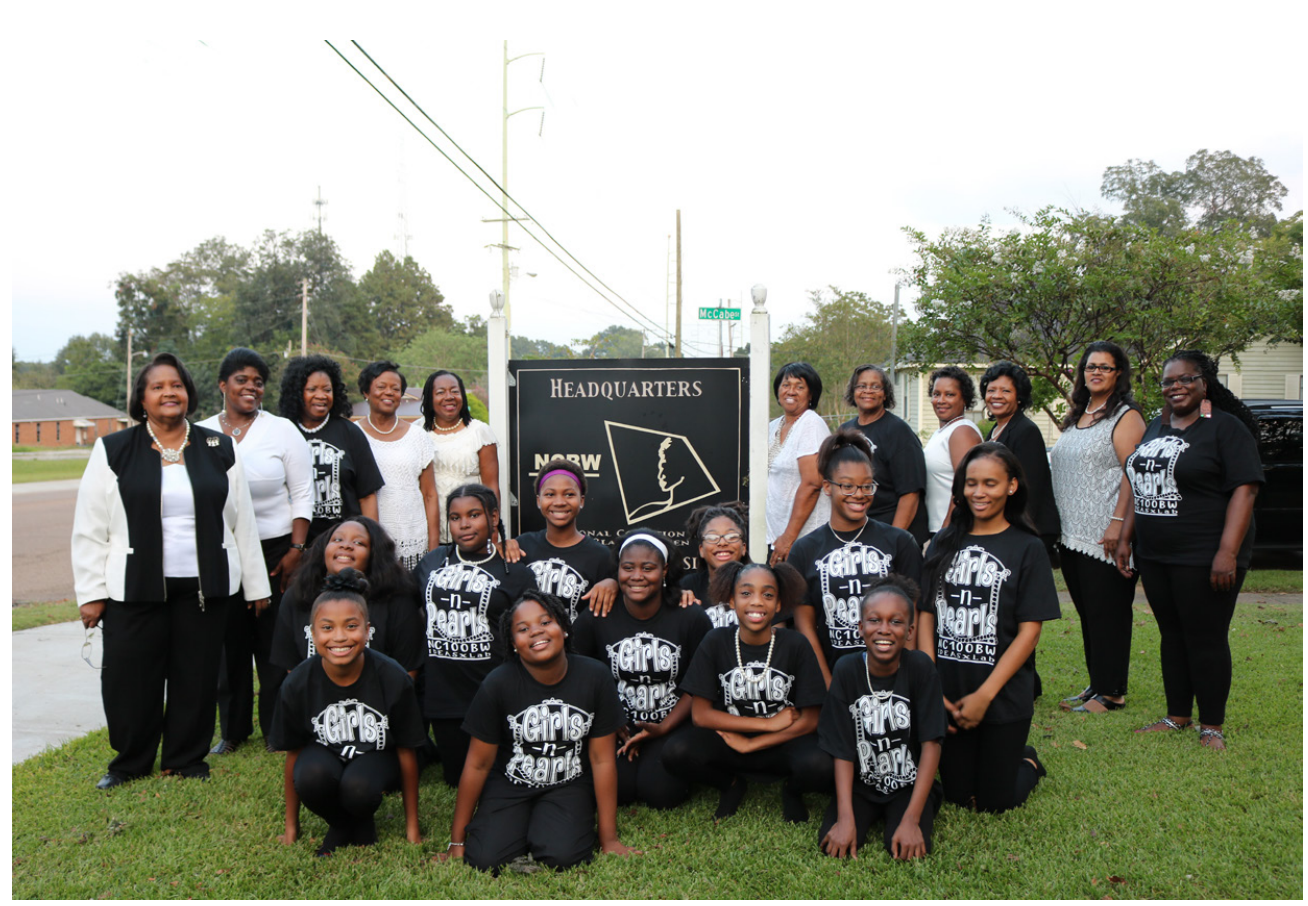

Em 2015 havia sido convidado a apresentar um projeto para a Bienal de

3 A recitação, récita ou declamação é uma forma de arte literária ou performance artística em que as letras de músicas, poemas ou histórias são faladas ao invés de cantadas. 
Havana, que teve influência determinante sobre esse trabalho posteriormente desenvolvido em Natchez. Uma confirmação de palavras de autoria esquecida, de que nos tempos da criação, as paralelas se encontram no infinito. Através de depoimentos de outros artistas e curadores que haviam participado de edições anteriores da mostra, soube da escassez de todo o tipo de material de construção na ilha. Itens básicos como madeira, tijolos, pregos e cimento eram controlados pelo governo e muito caros para serem adquiridos no mercado não oficial. Logo, o nível de restrição para os projetos apresentados era enorme. Este dado de carência, era um convite velado à potência. Foi-me oferecido como espaço de trabalho uma antiga escola para meninos, que após a mudança de regime, funcionou como centro de formação da nova juventude revolucionária. A cartilha empregada era "El Socialismo y el hombre en Cuba" (1965), escrita pelo próprio Guevara. Nesta instituição, atualmente fechada, havia um pátio central em terra batida disponível. A ideia era medir a altura do maior número possível de colaboradores do evento (artistas, curadores, funcionários, voluntários) e organiza-los alfabeticamente num quadrilátero em que o indivíduo de menor estatura estaria no nível do chão, e os demais posicionados em buracos com profundidades variadas nivelados de modo equânime. A tentativa era de criar uma grande escultura de reminiscências minimalistas, sem a adição de qualquer material. Apenas subtração. Infelizmente a obra não foi realizada, permanecendo o válido exercício da suposição.

Ao saber da convivência democrática das jovens no Mississipi, aplicar um sistema semelhante como arbitrariedade parecia fazer sentido. Principalmente tratando-se de indivíduos em fase de crescimento. Suas estaturas ainda variariam bastante, e o que quer que fosse construído, funcionaria como um retrato único do coletivo. Estava decidido a transformar o período de convivência com o grupo em algo que pudessem rememorar, servindo como índice de nosso encontro. Ao chegar em Natchez em abril de 2017, os primeiros gestos foram de mensuração.

Visitas regulares ao arquivo da cidade, ao museu de história afro-americana e entrevistas com seus responsáveis ${ }^{4}$ revelaram um fato curioso. Após a abolição oficial da escravidão em 1863, as primeiras comunidades livres na região ocorreram às margens do rio Mississipi sustentando-se, sobretudo, 
lavando roupas para as plantations houses localizadas na outra margem, já no estado da Luisiana. Podemos imaginar que comprar sabão para esta operação não era corriqueiro. Mas a condição de porto da área, gerador de um enorme intercâmbio de conhecimento desde a colonização francesa em 1716, garantia a disseminação de técnicas produtivas do utensílio a todos os extratos da população.

Existem diversas versões quanto ao surgimento do sabão. Um dos mitos mais difundidos remonta ao Monte Sapo, na Roma antiga. No local eram realizados sacrifícios de animais a partir do fogo. O contato entre a cinza vegetal e a gordura animal produzia uma substância, que ao entrar em contato com a chuva, acumulava-se nas margens do rio próximo ao local. Os moradores afirmavam que as roupas asseadas ali, ficavam mais limpas. Este aprendizado foi incorporado aos hábitos de higiene e hoje, a presença de meios detergentes é algo tão comum em nosso cotidiano, que já não refletimos o quanto esta descoberta possibilitou avanços imensuráveis na longevidade e expansão de nossa espécie. O embricamento entre a história da comunidade negra e o sabão abriam possibilidades instigantes, mas ainda não vislumbrávamos (equipe de produção e eu) quaisquer consequências.

Passamos a procurar empreendedores que fabricassem o produto. Afortunadamente havia uma loja na cidade, Scent From Natchez, de propriedade de mãe e filha afro-americanas, que trabalhavam a partir de antigas receitas artesanais (posteriormente descobrimos que o prefeito da cidade pertencia a família e iniciou a atividade por hobby com sua avó). O custo baixo dos componentes, sua semelhança visual com materiais clássicos da estatuária - como mármore, ou granito -, sua condição associada ao autocuidado e intimidade (confessemos, que o sabonete diário nos visita em lugares que apenas poucos frequentam) e a possibilidade de envolver comerciantes locais, foram os fatores pragmáticos que confirmaram aquilo que a intuição apontava. Se nos deixarmos fabular, podemos pensar o sabão como um bloco escultórico, em que somos o torno que molda. Algo que pelo contato com o epitélio plasma conteúdo e continente. O meio para tal? O elemento aquoso, imemoravelmente associado à passagem de tempo. "Não se banha duas vezes no mesmo rio", ensinou Heráclito de Éfeso.

Para os órgãos patrocinadores da residência o racismo deveria ser abordado através de suas consequências médicas. Os efeitos colaterais mais diretos sobre a saúde física são males como hipertensão, diabetes, obesidade, doenças cardiovasculares, abuso de drogas e violência doméstica, afetando uma camada da população que apresenta recursos escassos para se 
proteger ou regredir estes quadros. Um grupo de artistas não irá produzir fármacos, mas pode através de ideias e realizações, proporcionar meios imunosimbólicos de proteção, escape, ou até mesmo estratégias lúdicas que colaborem para a concreta mudança de comportamentos.

Os serviços de saúde norte-americanos raramente são oferecidos livres de cobranças. Para o ethos capitalista, a não gratuidade poderia estimular a competição e o oferecimento de atendimentos melhores a valores atrativos. No entanto não é assim que as coisas funcionam. Uma das plataformas de campanha e realizações de Barack Obama, presidente de 2009 a 2017, e que a gestão Trump esforça-se para derrubar sob o pretexto de inchamento da máquina estatal, foi o oferecimento de pacotes a preços possíveis, chamada "Lei de Proteção e Cuidado Acessível ao Paciente" (PPACA, na sigla sem inglês). Mais conhecida como Obamacare. Sua atuação é bem mais ampla e complexa, mas resumidamente, também envolve o aumento da faixa econômica que permite a inclusão no programa de saúde sem custos para pessoas de baixa renda (Medicaid) e a obrigatoriedade para empresas com mais de 50 funcionários em fornecer planos. Talvez esse seja um dos motivos pelos quais todos os cidadãos evitem ir ao médico e mergulhem num universo infindável de opções de remédios, vitaminas e automedicação.

Em conversas com moradores da cidade, percebemos que ervas, plantas e outras opções menos industrializadas não eram procuradas, apesar da rica diversidade da flora local. Estávamos pesquisando aromas para os sabonetes, simpáticos a encontra-los dentro do que era conhecido na região e não interessados em produzir um produto perfume Tylenol DC $750 \mathrm{mg}$. Buscávamos uma substância natural, que aliviasse os sintomas das doenças do legado colonial e aumentasse a sensibilidade da população para o fato de que talvez os bálsamos também brotassem no quintal de casa. Foi como chegamos à magnólia.

A flor descoberta pelo botânico Pierre Magnol (1638 - 1715), natural de países asiáticos como a China e o Japão, além de algumas regiões tropicais, é conhecida como a "flor da simpatia". Apesar da presença constante da heráldica da flor de lis pelo Mississipi, reminiscência francesa, é com a magnólia que o estado se identifica. Inúmeros jardins domésticos, parques e ruas as contém como símbolo de hospitalidade e acolhimento. É comum presentear novos amigos com as belas flores brancas. Na região são reportados exemplares particularmente grandes, com árvores de quase quarenta metros de altura. Visitei em Baton Rouge uma com trinta e circunferência de seis. Por caminhos que não se explicam pela lógica, 
mas pela confiança nos mistérios, os produtos fitoterápicos produzidos a partir da planta combatem enfermidades como ansiedade, depressão, pressão arterial, insônia e stress. Não poderíamos ter encontrado melhor parceira para exemplificar no meio ambiente, um invólucro de saúde para as síndromes que pretendíamos, ainda que poeticamente, atenuar.

Por outra auspiciosa tautocronia, uma outra flor originária das mesmas regiões da magnólia está associada em nossa história com a luta pelo fim da escravidão. A camélia serviu de símbolo para a Confederação Abolicionista, criada em 1883 no Rio de Janeiro, cujos encontros ocorriam, sobretudo, no jornal Gazeta da Tarde. A escolha é explicada por sua grande produção no Quilombo do Leblon, chácara do português José de Seixas Magalhães, protegido da princesa e a quem fornecia regularmente a flor ao Palácio Isabel, posteriormente renomeado Palácio Guanabara, hoje sede oficial do governo do Rio de Janeiro. A presença da flor em jardins de casas particulares, representava uma espécie de senha para escravos fugidos, revelando que ali encontrariam abrigo. Assim como para a identificação nas ruas daqueles simpáticos à causa, que a sustentavam como broche em suas vestimentas. Em treze de maio de 1888, durante a assinatura da Lei Áurea, Isabel recebeu dois buquês de camélias, um artificial e outro natural.

Figura 3 Equity Plataform, 2017. Instalação montada utilizando placas de sabão com essência de magnólia

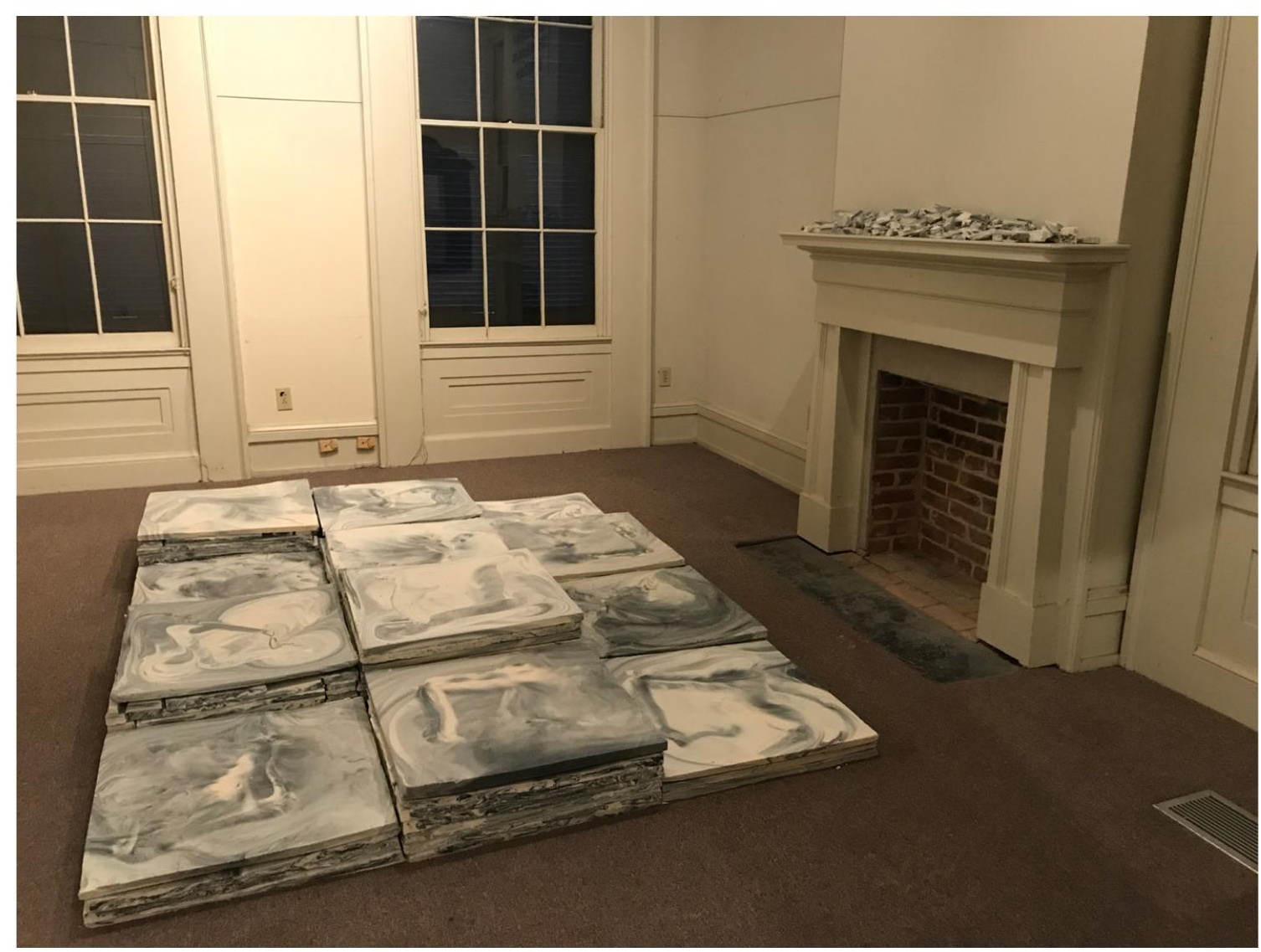


Ainda em abril, durante a primeira visita, uma das atividades desenvolvidas por Hannah, foi um fim de semana de troca de depoimentos intitulado "If you can see, you can be it", em que cada jovem deveria escrever três características positivas que gostariam de possuir no futuro. Nesta ocasião o grupo também encontrou um nome para si, que passou a se chamar "Girls'n Pearls", numa associação direta do objeto à feminilidade e beleza. No entanto, ao saber deste título, camadas de significados ligados ao nome emergiram, desdobrando outra peça escultórica.

As pérolas são as únicas gemas de origem animal. Sua formação se dá como um mecanismo de autodefesa a invasores. Ao detectar a presença de corpos estranhos a ostra libera uma substância, conhecida como nácar, que isola e recobre o parasita. Na natureza o fenômeno é muito raro, pois a ostra já se defende bastante bem com sua concha, ocorrendo uma vez em cada dez mil animais. No entanto, no início do século XX os japoneses inventaram uma forma simples de acelerar o processo, introduzindo uma pequena quantidade de madrepérola, com três quartos do tamanho final desejado, no interior do organismo. Este dado nos oferece a possibilidade de percebermos as pérolas como emergência de beleza, a partir da integração de traumas.

Certa ocasião, em conversa com o escultor Nelson Félix, soube de um projeto seu rejeitado pela $\mathrm{H}$. Stern. Ao ser convidado para o desenvolvimento de um ornamento para a marca, sugeriu colocar dentro das ostras diamantes para serem encapsulados. Os proprietários dos adornos não teriam acesso visual aos brilhantes, apenas presumiriam que continham preciosos recheios. A ideia aparece em "O Oco" vídeo de 1992, realizado pela extinta RioArte e com direção de Luís Felipe Sá. O ocultamento e a crença como produtores de valor, recordam também um antigo projeto de Tunga. Há histórias, realmente não encontrei fontes documentais sobre o fato, de que ao ser procurado para a construção de um monumento para cidade de Angra dos Reis, no litoral carioca, sugeriu como obra três grandes esferas de ferro. Elas seriam preenchidas de mirra, ouro e incenso e, após hermeticamente seladas, submergidas durante uma solenidade pública. Por razões prosaicas de compreender, a prefeitura também não comissionou o projeto. Mas em devaneios íntimos, imagino vislumbrar durante a maré baixa três delicadas corcovas refletindo a luz do sol. Avistamentos das ovas de Bahamut, o gigantesco peixe da mitologia árabe que carrega Kujata em suas costas. Tais miragens seriam raras, ocorrendo poucas vezes por ano e apenas aos com paz de espírito.

A redondeza é o motivo cosmogônico do surgimento da vida. Na capa do 
Figuras 4 e 5 Button Soap, 2017. Molde em silicone, sabão, aço inoxidável e pérola.
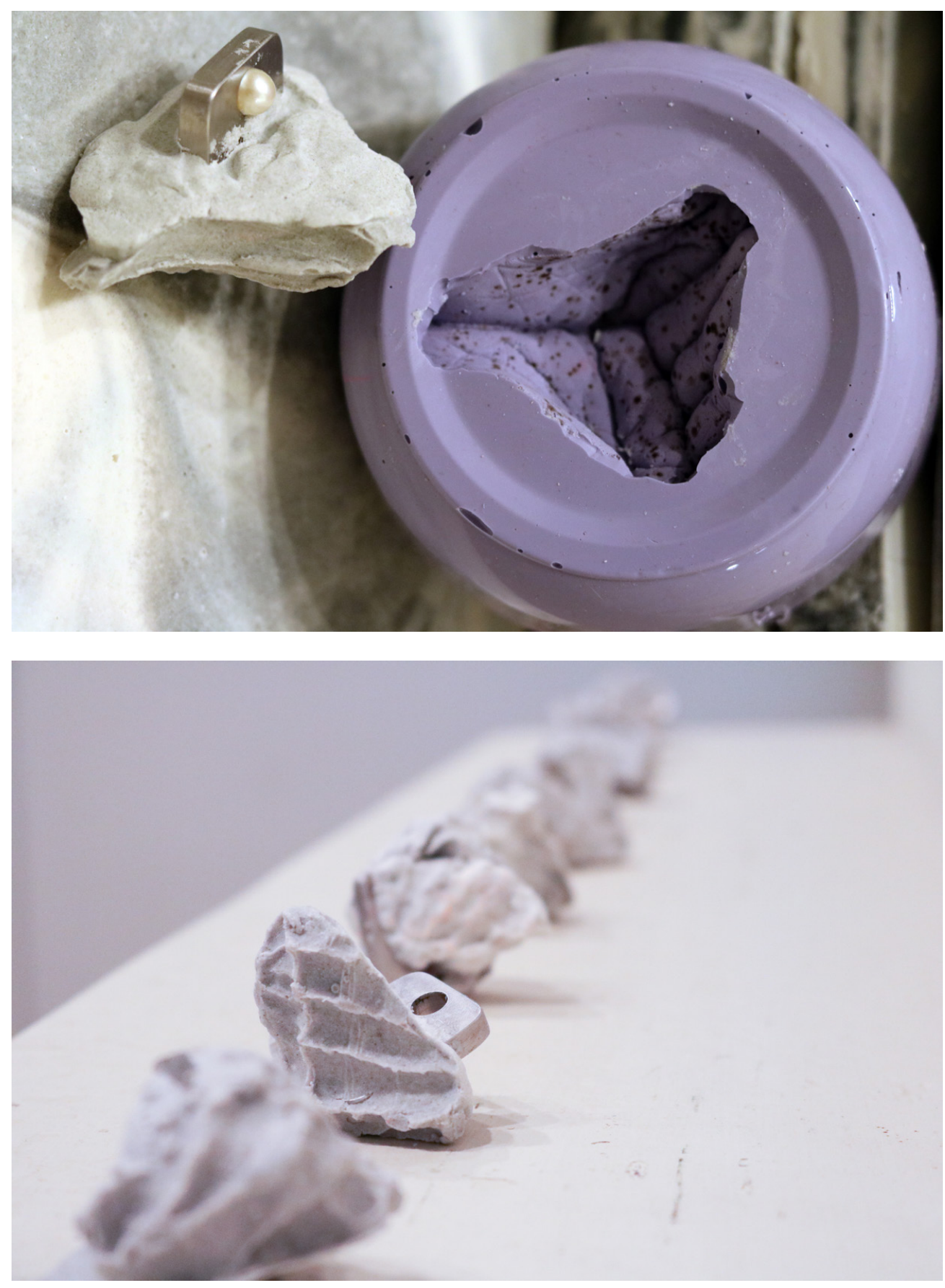

De generatione animalium, de William Harvey $(1651)^{5}$, vemos Júpiter segurando em suas mãos duas metades de um ovo. $O$ deus assiste à profanação do invólucro perfeito, de onde golfinhos, crianças e alces emergem. As

5 SLOTERDIJK, Peter. Esferas I: Bolhas. São Paulo: Estação Liberdade, 2016. 
jovens de Natchez também experimentaram uma gestação, a partir de um útero externo, em que aninharam potencias de geração para si mesmas. Com o auxílio da artista local Lorraine Griffin e seu marido, retiramos moldes do espaço negativo das mãos das adolescentes posicionadas em formato de concha. No interior do vão colocamos uma placa de aço inoxidável, gravada com as palavras que elegeram durante a dinâmica com Hannah, realizada anteriormente. O suporte também trazia uma concavidade para conter uma pérola. Cada uma das jovens foi responsável por derramar o sabão de magnólia líquido em seu molde individual. Após seco e desmoldado, foi recomendado que guardassem o objeto como uma relíquia e o usassem num futuro longínquo. A diluição da capsula temporal confirmará se habitam a égide daquilo que desejaram.

O que é roubar um banco diante do crime de se fundar um banco? ${ }^{6} \mathrm{Um}$ modelo de negócios como o WalMart, não é apenas um magazine labiríntico. Ou seus códigos de barra, caixas registradoras, câmeras de segurança e praças de alimentação saturadas de açúcar, sal e gordura. É também os campos de monocultura, autopistas, drones e máquinas inteligentes, que em breve substituirão a já excessivamente explorada mão de obra que mantém o circo do espetáculo em funcionamento. Dizem que a fábrica do futuro terá apenas 3 funcionários. Um homem, um cão e um robô. O humano para botar comida para o animal e o cão para não deixar o homem tocar o autômato.

Natchez apresenta uma série de características comuns a comunidades interioranas dos Estados Unidos, principalmente ao sul, que convivem com os impactos sobre suas economias da presença de grandes cadeias multinacionais e shopping centers. Núcleos urbanos pequenos ligam-se as cidades maiores por rodovias. À margem das highways, unidades da Walgreens, Office Depot, McDonald's, C\&A, Boots, entre outras, proliferam-se sufocando os empreendimentos locais e esvaziando os centros de todo o tipo de firmas e serviços. Além das consequências diretas que geram nos empregos, apesar da abertura de alguns postos, uma das implicações deste quadro é também o surgimento dos "desertos alimentares". Extensas áreas urbanizadas em que é difícil encontrar comida não processada e itens de consumo não industrializados. Na grande maioria das vezes, os bairros detêm apenas lojas de conveniência em postos de gasolina e restaurantes fastfood, decrescendo a qualidade da alimentação. As sequelas oriundas 
de tal constrição corporativa, portanto, aparecem no modo como os habitantes sustentam seus corpos e suas atividades remuneradas, constituindo um ciclo silencioso, perverso e difícil de ser corrompido.

Procurávamos ainda articular mais algum componente que revalorizasse os negócios locais e, afortunadamente, gerasse alguma renda aos mesmos e a coligação. Trabalhar com produtores de sabão era um caminho, mas ainda não o suficiente. Foi de mais uma visita ao passado histórico da cidade, que emergiu um objeto associado a triste fonte de sustento da região por centenas de anos. No sítio arqueológico onde ocorriam práticas comerciais dos protoconglomerados, que hoje denominamos multinacionais. Um dos artefatos mais comuns encontrados em Forks of the Road, o mercado de escravos de Natchez, foram botões de roupas. Por 300 anos o local abrigou o segundo maior posto de compra e venda humanos do Deep South. Ali, pertences daqueles que foram vendidos e daqueles que os vendiam, remanesciam indiscerníveis sob a terra, em abundância. Estes pequenos itens eram facilmente associados a um indivíduo e a coletividade que compunham. Tanto por sua constituição indumentária, quanto por sua condição modular, exemplificando e mensurando as incontáveis vidas, cujas histórias estão associadas ao lugar.

Tínhamos até então as "conchas" pessoais de cada membra da coligação

Figura 6 Sabonete e botão de roupa construído a partir do tronco da árvore da magnólia.

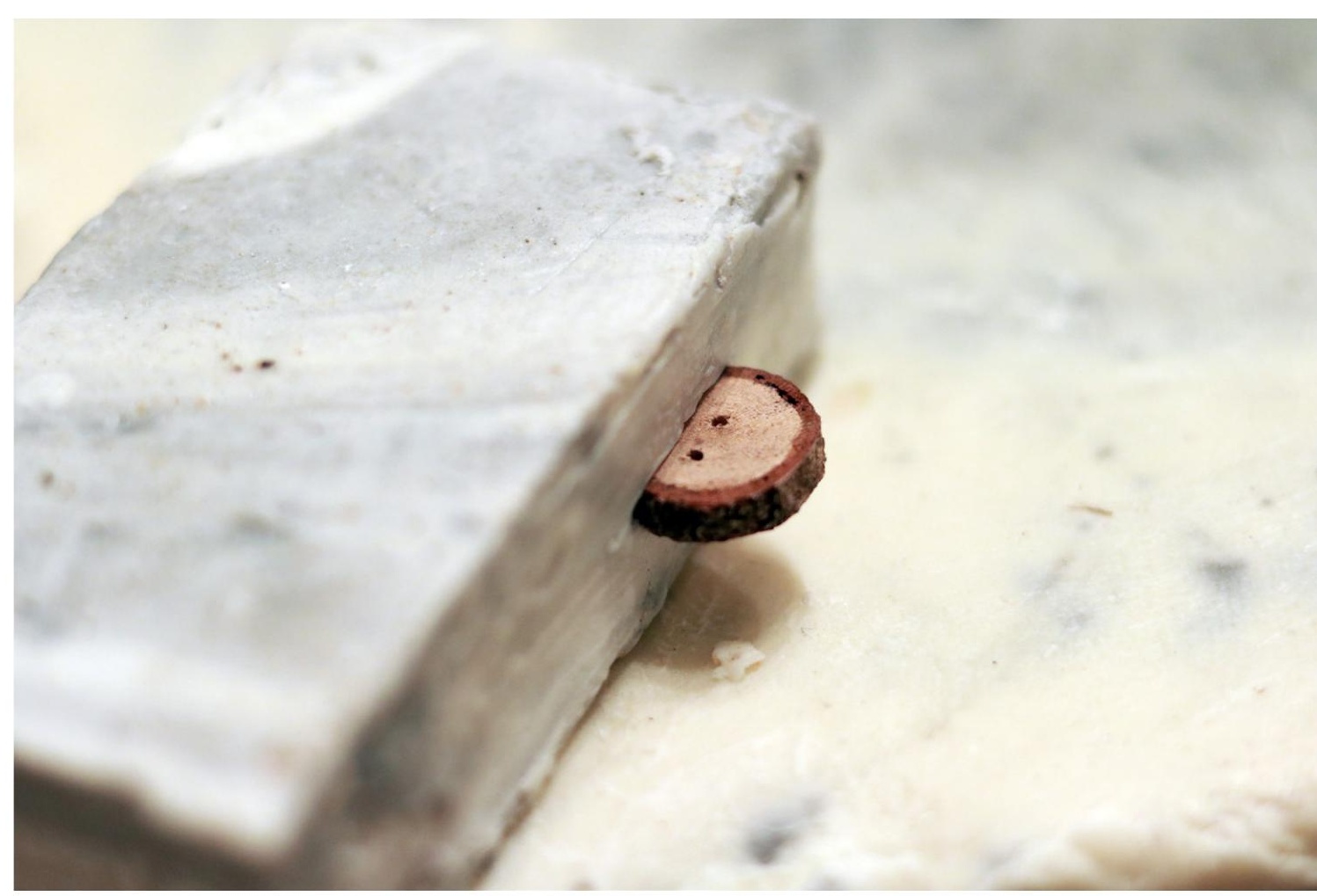


Figura 7 Sabonete já embalado para venda contendo texto de autoria de Houston, ator e guia turístico. preenchidas com pérolas, e um grande pódio sendo desenvolvido com placas de sabão. Ambos do mesmo material, com o mesmo aroma e o mesmo potencial curativo pelo autocuidado. Mas com a distinção de que uma peça já estava individualizada para consumo e a outra era um monumento inerte de 350 quilos. Neste ponto, o destino das obras amalgamou-se. Determinamos que após a ativação da plataforma por Hannah, em meados de setembro 2017 na sede da NC100BW, iríamos fatiar a estrutura em barras. Fatiar e rechear cada barra remanescente com um botão de roupa. A estimativa era de conseguir 2000 unidades. No entanto, antes a artista conduziu uma performance aberta ao público, em que as jovens subiram sobre a estrutura com o braço direito estendido e punhos cerrados - em referência à saudação dos Panteras Negras, celebrizada pelos atletas Tommie Smith e John Carlos nas Olimpíadas de 1968 (México) - e cantaram juntas a música "Rise Up" de Andra Day. O ato precedido pela declamação de um potente poema de Hannah.

Durante uma semana, com ajuda das meninas, das tutoras e da equipe de produção, todos revezando-se voluntariamente, cortamos e embalamos toda a escultura e inserimos em cada barra um botão de madeira de magnólia, produzido pelo mesmo casal que havia realizado os moldes em silicone para as obras. As Barras foram vendidas na sede da coligação, em 
lojas para turistas e pelo site da Xlab IDEAS pelo valor de 10 dólares. O dinheiro arrecado foi convertido para as atividades da NC100BW. Carimbado como rótulo, um texto do ator e guia turístico local Jeremy Houston, afirmava que ali havia um botão oculto, que após o sabonete usado, poderia ser costurado em sua roupa e servir de símbolo pelo movimento contra a segregação racial. Uma delicada microescultura que identificaria na cidade os simpáticos à urgente causa. Uma camélia. Uma pérola.

O leitor pode ter reparado que o tom escolhido para a escrita deste artigo não se apoia em autores respeitados, não inaugurou discussões sobre os temas e, até certo ponto, foi leviano com o protocolo científico. Descreveu linearmente os inícios e as resultantes. Parte deste cuidado deve-se à natureza delicada do assunto. Tenho a consciência de ter sido acolhido dentro de um ambiente muito particular e convidado a deliberar sobre algo que desconheço. Ou que talvez para alguns, não deveria sequer avançar sobre. Portanto, optei por um discurso simples, que confiou no possível poético obtido, para superar territórios conceituais e de discurso.

Vivemos num momento histórico em que as diferenças não são mais pontos de partida para as uniões, mas também para o entrincheiramento. E a palavra tem uma responsabilidade muito grande neste sentido. Como dela um convidado circunstancial sou, escolhi descrever um processo atravessado por indivíduos de contextos culturais, etários, de gênero e raciais

Figura 8 Hannah Drake e as jovens da NC100BW sobre a plataforma de sabão.

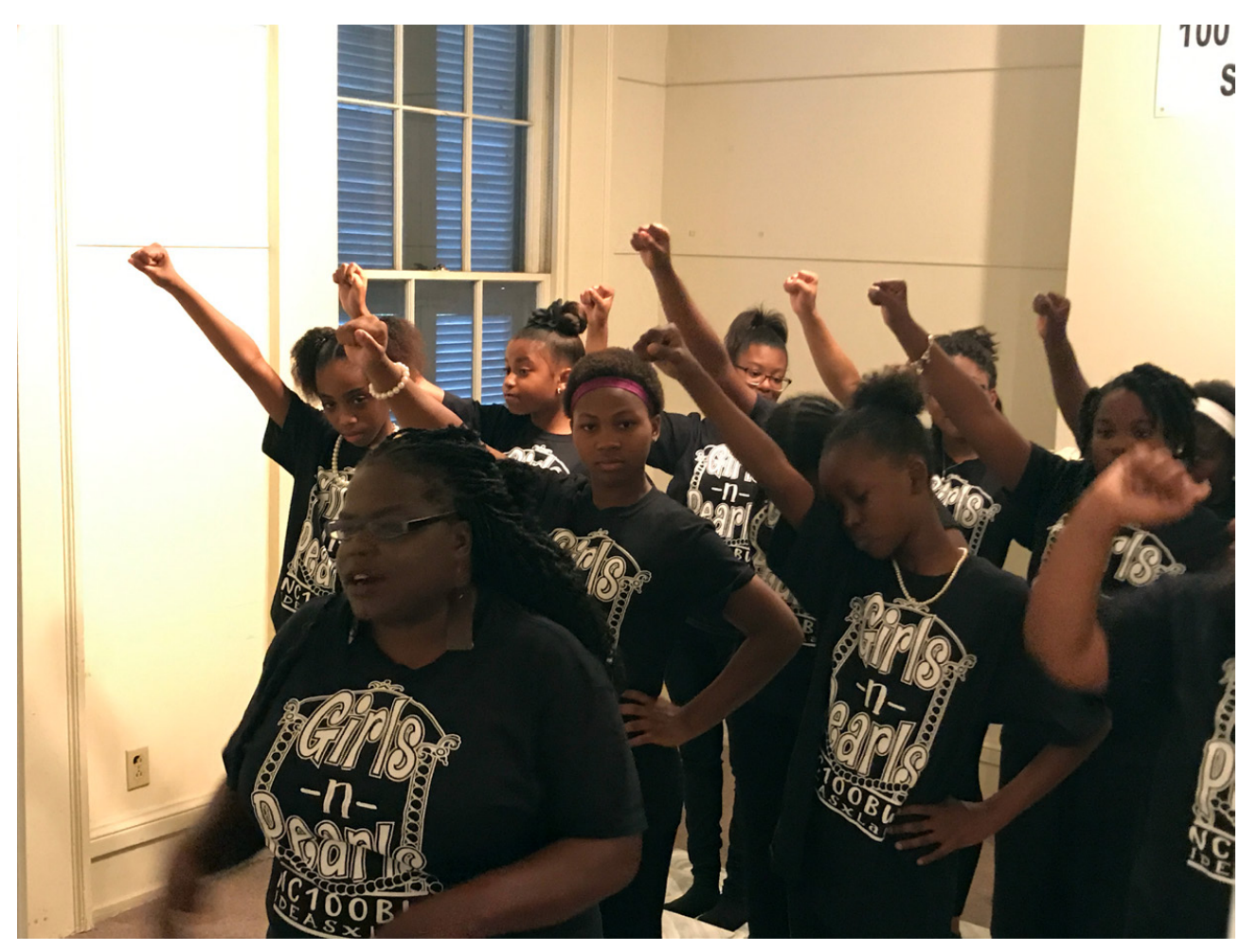


distintos - que apenas suportaram incertezas até que as consequências formais de seus gestos coletivos aportassem -, de modo leve. Problematizações críticas importantes podem ter ficado de fora, mas ao artista foi oferecida voz, mais do que ao pesquisador.

Vivemos um cotidiano de excessos, de hiperestímulos, de pouca contemplação e silêncio. Todos sofremos os resultados destes ambientes tóxicos e ao invés de regredir na quantidade de informação que consumimos (ou talvez de consumo disfarçado de informação), confiamos que é aumentando a atividade mental, que conseguiremos sair de onde nos encarceramos. Porém é o corpo e o afeto que oferecerão caminhos. Para tanto, é preciso desenvolver uma natureza de observação e inclusão, que admite novamente a intuição, o mistério e qualquer outra linha de fuga que leve ao devaneio e à aventura. Se possível ao fracasso também, tão comum no vocabulário da criação, mas que passamos a rejeitar em nome da competitividade. Sobretudo nos meios acadêmicos e institucionais.

De modo algum devemos nos voltar contra os espaços que por tanto tempo nos acolheram, lutam para continuar num cenário de repressão intelectual e permitiram o desenvolvimento de investigações até certo ponto excêntricas, como podem ser as do campo da arte. Mas alertar que talvez estejamos realizando-as numa velocidade incapaz de serem incorporadas, pois desrespeitamos o tempo da imaginação pelo do pragmatismo e do espetáculo. Nunca produzimos imagens tão nítidas, de slow motion tão definidos e tão cintilantes quanto agora e, cujo apetite de absorção, só se compara à velocidade com que são descartas.

Há um ditado tibetano, que sintetiza os encontros: "No topo da montanha avistei um animal. Na base descobri tratar-se de um homem. Ao me aproximar era meu irmão." Oportunidades como a desenvolvida em Natchez, nos rememoram que o potencial criador está ao alcance de todos, desde que sejam abertas interlocuções e se ofereça tempo de maturação. Algo só alcançável quando todos os envolvidos permitem um processo de avizinhamento que contém algum método, anarquia e disponibilidade à serendipidade. Tendemos a eleger certas fontes ou eventos como hierarquicamente superiores a outros em ter capacidade de comunicação e construção de conceitos. Mas o poder do acaso não pode ser subestimado. Horizontalizar, não julgar, suspender classificações como "erro" e "acerto", substituindo-as pela errância, é fundamental para tornar nossas existências instrumentos insurgentes de uma ontologia poética da presença. Sigamos ciganos.

Este é um artigo publicado em acesso aberto sob uma licença Creative Commons $(\mathbf{c c})$ EY 